\title{
Conformity to Peer Pressure in Preschool Children
}

\author{
Daniel B. M. Haun \\ Max Planck Institute for Evolutionary Anthropology; \\ Max Planck Institute for Psycholinguistics; \\ and University of Portsmouth
}

\author{
Michael Tomasello \\ Max Planck Institute for \\ Evolutionary Anthropology
}

\begin{abstract}
Both adults and adolescents often conform their behavior and opinions to peer groups, even when they themselves know better. The current study investigated this phenomenon in 24 groups of 4 children between $4 ; 2$ and 4;9 years of age. Children often made their judgments conform to those of 3 peers, who had made obviously erroneous but unanimous public judgments right before them. A follow-up study with 18 groups of 4 children between 4;0 and 4;6 years of age revealed that children did not change their "real" judgment of the situation, but only their public expression of it. Preschool children are subject to peer pressure, indicating sensitivity to peers as a primary social reference group already during the preschool years.
\end{abstract}

Humans conform. With little or no reflection, we adopt many functionless and ever-changing fads and fashions of those around us. We not only conform to arbitrary fashions but also conform to majority opinion when we know better ourselves. The experimental demonstration of individual's knowingly giving false responses to conform to an erroneous majority has sparked decades of scientific discourse and wonder (Asch, 1956; Cialdini \& Goldstein, 2004). To contrast this situation with one in which there is simple conformity to a majority (e.g., in choosing one style of shirt over another) we call it "strong conformity." Despite its negative connotation in much intellectual discourse, conformity, especially strong conformity, serves a crucially important function in the transmission of human culture by promoting quick and stable in-group uniformity, which then stabilizes between-group cultural diversity over time (Henrich \& Boyd, 1998; Henrich \& Henrich, 2007).

Genetically similar people, living in physically similar environments, demonstrate dramatic differences in their traditions, behavior, and cognition

We are indebted to Nadja Richter for her extraordinary coordination and support during all stages of this project. We are grateful to Constanze Weiske, Juliane Dauksch, Christiane Markmann, Martina Wittig, Stefanie Voigt, Kristin Schotte, and Franziska Kröbel for their assistance and the children, caretakers and kindergarten teachers for their support. We also extend thanks to Hannes Rakoczy, Jonathan Beier, Bridget Waller, Katja Liebal and Yvonne Rekers for guidance. This research was funded by the Max Planck Society.

Correspondence concerning this article should be addressed to Daniel Haun, Max Planck Institute for Evolutionary Anthropology, Research Group for Comparative Cognitive Anthropology, Deutscher Platz 6, 04103 Leipzig, Germany. Electronic mail may be sent to haun@eva.mpg.de. (e.g., Dehaene, Izard, Spelke, \& Pica, 2008; Goldstein, Davidoff, \& Roberson, 2009; Haun \& Rapold, 2009; Haun, Rapold, Call, Janzen, \& Levinson, 2006; Majid, Bowerman, Kita, Haun, \& Levinson, 2004; Malinowski, 1929; Segall, Campbell, \& Herskovits, 1963). These differences are maintained through time despite factors such as migration and intermarriage, which constantly mix individuals between neighboring groups (Barth, 1969). Given a long enough time span, the mixing of languages, traditions, and knowledge should cause most differences between groups to disappear, while, in fact, they do not. Instead of diminishing, crossgroup differences in humans are maintained by a complex set of sociopsychological mechanisms including, importantly, a strong tendency to conform to the behavior of those in one's group (Henrich \& Boyd, 1998).

The behavioral repertoire of one's group is acquired from a young age. Children quickly and strategically learn skills by observing adult models (Gergely, Bekkering, \& Kiraly, 2002; Schwier, van Maanen, Carpenter, \& Tomasello, 2006; Tomasello, 1999). When confronted with multiple models presenting conflicting information, preschool children tend to trust those adults they have seen as conformists rather than dissenters (Corriveau, Fusaro, \& Harris, 2009). When confronted with adult models presenting information that stands in conflict with their own, preschoolers will often suc-

(C) 2011 The Authors

Child Development (c) 2011 Society for Research in Child Development, Inc. All rights reserved. 0009-3920/2011/8206-0005

DOI: $10.1111 / j .1467-8624.2011 .01666 . x$ 
cumb to the adult's point of view (Ma \& Ganea, 2009) as well as to a majority of adults (Corriveau \& Harris, 2010). In summary, already young children are sensitive to information provided by adults, strategically considering motivations, social context, and authority. Comparatively little is known about children's strategies when confronted with information provided by peers. This is important because conformity to adults may rest, ultimately, on fear of punishment. Strong conformity to peers-reversing one's own behavior or opinion under peer group pressure even when one knows better-has been documented in school-age children and adolescents (Berndt, 1979; Bishop \& Beckman, 1971; Costanzo \& Shaw, 1966). Two studies previously attempted to test strong conformity in children below 5 years of age (Corriveau \& Harris, 2010; Walker \& Andrade, 1996). Corriveau and Harris (2010) tested preschoolers' susceptibility to the unanimous but erroneous opinion of a televised majority of adults. They report that children sometimes defer to the adult majority unless the children's response is of immediate practical relevance. It remains unclear whether preschoolers in this situation react to adults' authority only (Ma \& Ganea, 2009). This confound with obedience is absent in a slightly older study by Walker and Andrade (1996) using a set of same-age stooges. They report comparable levels of conform responses. Interestingly, they report a decline in conform responses between 3 and 17 years of age. However, partly due to the difficulty of instructing peers as stooges, this study had only two critical trials in the preschool-age group and so did not allow for a detailed analysis of children's behavior. Additionally, both studies do not allow interpretations of preschooler's underlying motivations: have the children actually changed their minds as a result of the majority opinion, or are they only acting as if they have to mollify the others.

In the present study, we focused on strong conformity to a peer group in preschoolers. We might think of conformity of this type as signaling the origins of peers as a primary social reference group for young children. The age at which we should expect strong conformity to peer pressure is not clear. Children only start to understand and produce self-presentational behaviors among peers from about the age of 8 onward (Banerjee, 2002). However, it is conceivable that they are sensitive to peer pressure at an earlier age.

In this study, we therefore employed a paradigm very similar to that of the original Asch (1956) experiments, but with 4 -year-old children. In the crucial experimental condition, an individual subject was asked to make an "easy" perceptual judgment immediately after three peers had announced a clearly wrong but unanimous judgment in that same task. In a second study we sought to establish if children would submit to peer pressure equally readily if their own judgments were given publicly in front of the peers or privately to the experimenter only-thus determining whether the peers influenced their "real" opinion, or only their public expression of it.

\section{Experiment 1}

In the first study, we created an experimental situation as comparable as possible to Asch's (1956) original experimental design. Subjects were 4-year-old children, and the reference group was three other 4-year-old children.

\section{Method}

Participants. A total of 96 four-year-old children (mean age $=53$ months, $S D=1.21$ months, range $=$ 50-57 months) participated in this study. Children were tested in 24 gender-mixed groups of 4 children each. Every group consisted of 3 children forming a unanimous majority and one child in the minority position ("minority child"). All children in a group went to the same kindergarten (where they were tested) and knew each other before the study. Among the 24 minority children there were an equal number of boys and girls. Where possible, the groups were gender balanced $(13 / 24)$. In all other groups, the child in the gender minority was never the minority child. All children were recruited from local kindergartens, were native German speakers of normal ability range, and came from mixed socioeconomic backgrounds. As too many errors might make the majority appear nonunanimous, we excluded all groups in which the majority children made significantly more mistakes than could be expected based on the average baseline performance on the point before trials (see the Procedure). Given approximately 5\% errors in the point before task (appr. 15\% for all three majority children taken together), the significance level is crossed at 10 errors (one-sample $t$ test against 15\%: $t=2.1, d f=29, p=.045)$. In consequence, two groups were excluded due to more than one third nonunanimous majority responses. Furthermore, two additional groups were excluded due to experimenter error. Children were free to choose not to 
participate at all times (one quit). The samples reported above are the final numbers after exclusions.

Materials. We created picture books in which each double page contained four replications of the same cartoon animal in three different sizes (large $=4.5 \times 4.5 \mathrm{~cm}$, middle $=3.15 \times 3.15 \mathrm{~cm}$, small $=$ $1.8 \times 1.8 \mathrm{~cm}$ ). Three animals (large, middle, and small in pseudorandomized order) were printed on the left-hand page, one animal (pseudorandomly either large, middle, or small) was printed on the right-hand page (Figure 1B). Each book contained 30 double pages with a different kind of animal on each. In each session, three of the books were identical (majority books), whereas one book was identical in the order of animals across pages but deviated on some trials as to which size was printed on the right-hand side (minority books). In this way we create a minority facing a unanimous majority of three peers. To create four small booths for the children to sit in we used two intersecting wooden boards $(85 \times 90 \mathrm{~cm}$ each; see Figure $1 \mathrm{~A})$. Each booth was color coded (orange, green, blue, red) and fitted with a color-matching pillow and a small alien-shaped bedside lamp. Color distribution across social status positions was counterbalanced across subjects. All behavior was recorded by four $\mathrm{dv}$-camcorders (one for each child) on a four-way split screen.

Procedure. Instruction Session 1: Children sat in a row facing the Experimenter (E). E showed the children warm-up picture books with six sets of animals. During this warm-up period E established the three left-hand animals on each double page as a family picture (large $=$ daddy, middle $=$ mommy, small $=$ baby). The right side of the same double page pictured a replication of one of the three animals. E explained that one of the three family members had run over to the right-hand side. The children were asked to identify this individual picture as daddy, mommy, or baby. Children were probed individually to ensure understanding. Then children were asked to identify the single individ- ual by silently pointing to the corresponding individual in the family picture.

Next, E assigned one of the children to be the target child using the following procedure. The gender of the target child and the color of its booth (e.g., red) were determined prior to the session. After the warm-up, E first instructed the two children who were not of the predetermined gender to sit, for example, in the blue and orange booths. Then she instructed the two remaining children to choose one of the leftover booths. The child ending up in the red booth was the target child (minority). The other children formed the majority. From this point on, E only ever gave neutral feedback to children's responses.

Point Before: Each child was asked in succession to silently point to the animal in the family picture corresponding in size to the single individual on the opposite page. The target child always responded last. This block lasted six trials. The purpose of the point before trials was to determine the basic performance level of children in this relative size judgment task.

Instruction Session 2: After completing the six pointing trials, all children were asked to leave their booths and sit in a row facing E. They were now instructed to identify the single individual by saying out loud "Papa," "Mama," or "Baby" (daddy, mommy, baby). Further, children were told that they were only allowed to talk when their lamp was switched on. The lamp was meant to ensure that children do not speak between trials. Then children were sent back in their booths.

Speak trials: Each group completed 18 speak trials. On any trial, children were asked individually in succession to say out loud the family member, which had moved to the opposite page. The target child always responded last. On 12 of these trials the minority book deviated from the majority books (conflict trials). On the other 6 trials (Trials 1, 2, 3, 8,13 , and 18) all four books were identical (no conflict trials). This trial order replicates exactly Asch's original design (Asch, 1956).
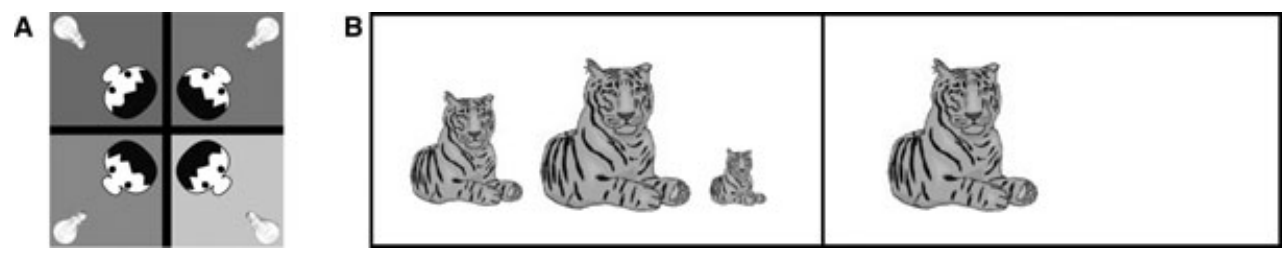

Figure 1. (A) Experimental setup from a birds-eye perspective. Light bulbs identify the location of the lamps. (B) Example of a stimulus from the relative size judgment task. 
Point After: Finally, the children received six more silent pointing trials. Children were again asked individually in succession to silently point to the animal in the family picture corresponding in size to the single individual on the opposite page. The target child always responded last.

Debriefing: Finally, after children had been told that the experiment had ended, E, in a surprised manner, stated that she had accidentally mixed up one of the books. She then asked if anyone had noticed something odd about his or her book. Then she demonstrated for everyone to see that one of the books was different from the others and apologized for her mistake. With this procedure, we attempted to prevent any negative consequences for the minority child's self-esteem or reputation.

Data scoring and analysis. We videotaped all trials. We scored the responses (pointing and speaking) from videotapes and/or in situ notes. The pointing trials serve as an ability check, probing children's individual performance on the task at the beginning and end of the session. We further planned to test whether children's performance differed between the speak-no conflict and speakconflict trials indicating an effect of peer pressure. Our dependent variable was the percentage of correct responses, meaning reporting what was in the book. Our independent variables were conflict as a within-subject factor (speak-no conflict, speakconflict) and gender (male, female) as a betweensubject factor. Majority children displayed nearly perfect performance in all conditions (Figure 2). Consequently, there were no significant differences between conditions or genders, ensuring that boys and girls were equally able to do the task and our stimuli were equal in difficulty across point and speak trials and both levels of conflict.

\section{Results}

Analyzing the minority children, the pointing trials served as an ability check. Performance was close to perfect on these trials, showing that the minority children, just like the majority children could easily identify the correct animal when tested individually, at the beginning as well as at the end of the session (point before: $M=0.97, S E=0.013$; point after: $M=0.97, S E=0.008), t(23)=0.253$, $p>$.5. All reported $p$ values in this manuscript are two-tailed. Alpha was set at .05, and thus all results reported as significant are $p<.05$. All effect sizes are calculated using the $G^{*}$ Power software (Faul, Erdfelder, Lang, \& Buchner, 2007).

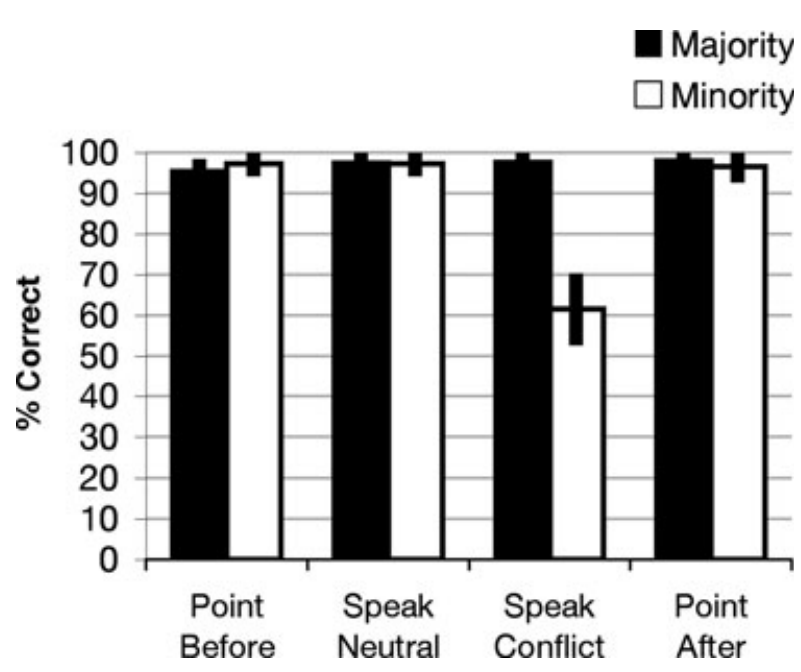

Figure 2. Mean percent correct $( \pm S E)$ for all four conditions of Experiment 1 for majority and minority children.

Most importantly, minority children performed significantly better in the speak-no conflict than in the speak-conflict condition (speak-no conflict: $M=0.97, \quad S E=0.013 ;$ speak-conflict: $M=0.61$, $S E=0.072)$, main effect: $F(1,22)=30.30, f=1.18$, demonstrating conformity to peers' opinion (Figure 2). This effect was significantly stronger in girls than in boys, interaction: $F(1,22)=6.86, f=0.56$. Furthermore, children were significantly slower to respond in speak-conflict than in speak-no conflict trials (conflict: $M=889 \mathrm{~ms}, S E=122$; no conflict: $M=617 \mathrm{~ms}, S E=119$ ), main effect: $t(23)=3.16$, Cohen's $d=1.3$.

Looking only at children's responses in the speak-conflict condition, minority children on average gave a correct account of the picture in front of them $52.8 \%$ of the time (SE $=7.04)$. On $37.5 \%$ of trials $(S E=7.45)$, they responded conform to the majority opinion, and on $2.4 \%$ of trials $(S E=0.94)$ they reported neither what was printed on the page nor the majority opinion. Of 24 children, 18 conformed at least once, out of which 10 conformed more often than not. During debriefing, children were asked if they had noticed their book was different. Of the 24 sessions, 22 included clear video footage of who responded to the question. Of those 22 minority children, only 5 stated to have realized their book to be different during debriefing. Of those 5 children, 4 conformed at least once, out of which only one conformed more often than not. Although the low numbers do not allow for a statistical comparison between children who reported noticing their book to be different and those who did not, the former seem to conform less. Children's level of conformity significantly 
decreased across trials (Pearson's correlation of mean levels of conformity across trials $r=-.764$, $N=12$ ). Similar effects to this were also reported by Corriveau and Harris (2010). This might, for example, be due to a growing mistrust toward the majority (Corriveau \& Harris, 2010) or the lack of negative consequences to autonomous responses on earlier trials. Boys and girls gave equal amounts of incorrect responses (boys: $M=2.08 \%, S E=1.09$; girls: $M=2.78 \%, S E=1.57$ ), but they differed to some extent in the correct (boys: $M=68.06 \%$, $S E=9.56$; girls: $M=37.5 \%, S E=9.91)$ and conform responses (boys: $M=23.61 \%, S E=8.06$; girls: $M=51.39 \%$, $S E=10.35$ ). While boys gave more correct responses than girls, girls gave more conform responses than boys.

\section{Discussion}

Four-year-old children performed extremely well in the relative size judgment task as indicated by the high performance in the point before and point after conditions. Hence, we assume that our participants clearly perceived the nature of the stimuli in front of them. In consequence, the exclusive drop in performance only in the minority children, only when they had to give a public response facing a unanimous opposition (speak-conflict condition), indicates a reaction to peer pressure. Children were also slower to respond on speak-conflict relative to speak-no conflict trials, potentially indicating effects of peer pressure. Our data show that in these conflict situations, children do not indiscriminately abandon and replace their private perception of reality but adapt their responses to match the majority opinion. Overall, our participants, just like it is usually found in adults (Asch, 1956), accurately report reality more often than not. It is fair to say that reality holds a greater influence on individual's responses than peer pressure. However, further analysis of our data showed that in this experiment this was not true for both genders equally. While true for boys, girls in fact conformed more often than they accurately described reality in speak-conflict trials. In comparison to boys, girls conformed more than twice as often. This gender difference, though more pronounced in this sample, has regularly been reported in adults (Bond \& Smith, 1996).

Experiment 1 demonstrated strong conformity (conformity against the child's own judgment) to peer pressure in preschool children. However, the motivation behind children's conformity remains unclear. Adults conform following two different motivations (Deutsch \& Gerard, 1955): behavioral optimization (informational conformity) and social approval (social conformity). Informational conformity describes the motivation to adopt a majority position because it is taken to be a trustworthy source of information about a shared objective reality. Social conformity describes the motivation to adopt a majority position because of the social benefits. Conforming to the majority not only minimizes social conflict but also actively heightens the group's perception of the individual. Accepting the fact that informational and social motivations are often interrelated (Cialdini \& Goldstein, 2004), Experiment 2 attempted to further distinguish between children's motivations to conform: They were asked to make their response in public or privately after having been exposed to the majority opinion. While an informational motivation would affect both situations equally, social motivations would only matter if the individual's responses were public.

\section{Experiment 2}

Our aim was to create an experimental situation as comparable as possible to Experiment 1 but that could additionally distinguish between informational and social conformist behavior. After being exposed to the majority opinion, children had to give either public or private responses, either when in agreement or when in conflict with the majority.

\section{Method}

Participants. A total of 72 four-year-old children (mean age $=53.64$ months, $S D=1.85$ months, range $=48-56$ months) participated in this study. Children were tested in 18 gender-mixed groups of 4 children each. Similar to Experiment 1, every group consisted of 3 children forming a unanimous majority and 1 child in the minority position. Among the 18 minority children, there were an equal number of boys and girls. Where possible, the groups were gender balanced (11/18). In all other groups, the child in the gender minority was never the minority child. All children were recruited from local kindergartens, were native German speakers of normal ability range, and came from mixed socioeconomic backgrounds. A total of seven groups were excluded, due to either more than nonunanimous majority responses (four excluded) or experimenter error (three excluded). Children were free to choose 
not to participate at all times (0 quit). Again, the samples reported above are the final numbers after exclusions.

Materials. We used the same stimuli as in Experiment 1 to create new picture books. Again, in each session, three of the picture books were identical (majority books), whereas one book was identical in the order of animals across pages, but deviated on some trials as to which size was printed on the right-hand side (minority books). The physical setup was also identical to Experiment 1 (see Figure 1A). Color distribution across social status positions was again counterbalanced across subjects. Sessions were recorded by two dv-camcorders (one for two neighboring children).

Procedure. Instruction: In addition to the instructions specified in Experiment 1, children were told that their lamp would indicate if they were supposed to say their response out loud or to silently point to the correct animal (switched off = point; switched on = speak). Again, children were probed individually to ensure understanding.

Next, E assigned one of the children to be the target child using the same procedure as in Experiment 1 .

Point Trials: The child was asked to silently point to the animal in the family picture corresponding in size to the single individual on the opposite page. The target child always responded last.

Speak Trials: The child was asked to say out loud the family member, which had moved to the opposite page.

Participants completed a total of 30 trials. On any given trial one of the four children might have to point. Each of the three majority children completed two pointing trials each, one in which all books were alike and one in which the minority child's book differed from the others. On these six trials the target child was always asked to speak. The six majority-point trials were introduced in order to not make the minority child feel excluded by being the only one who is asked to point. The remaining 24 trials the minority's responses were counterbalanced in a 2 (design response: point/ speak) $\times 2$ (conflict: books alike/books different). From the minority's perspective this split resulted in 6 point/no conflict, 6 point/conflict, 6 speak/no conflict, and 6 speak/conflict trials. Trial order was randomized with the restriction that the first three trials had to be no conflict trials and one of the majority children was first of the group to point. Target children did not behave significantly different in trials in which one member of the majority pointed silently, and hence only two majority opin- ions were audible and trials in which in all majority judgments could be heard. As a result, we collapsed them in our analysis.

Debriefing: Finally children were debriefed as in Experiment 1.

Data scoring and analysis. We videotaped all trials. We scored the responses (pointing and speaking) from videotapes and/or in situ notes. We conducted two separate mixed $2 \times 2 \times 2$ analyses of variance (ANOVAs) for majority and minority children, respectively. Our dependent variable was the percent of correct responses, meaning reporting what was in the book. Our independent variables were response (point, speak) and conflict (conflict, no conflict) as within-subject factors and gender (male, female) as a between-subject factor. Majority children displayed nearly perfect performance in all conditions (Figure 3). The ANOVA revealed no significant effects between conditions or genders in the majority children, ensuring that boys and girls were equally capable to do the task and our stimuli were equal in difficulty across conditions.

\section{Results}

Minority children were differently sensitive to a conflict with majority opinion depending whether their response was either private or public, significant interaction: $F(1,17)=6.39, f=0.61$. Children only behaved significantly different in pointing relative to the speaking trials when there was a conflict with the majority opinion, $t(17)=3.16$, Cohen's $d=1.5$ ). In conflict trials minority children

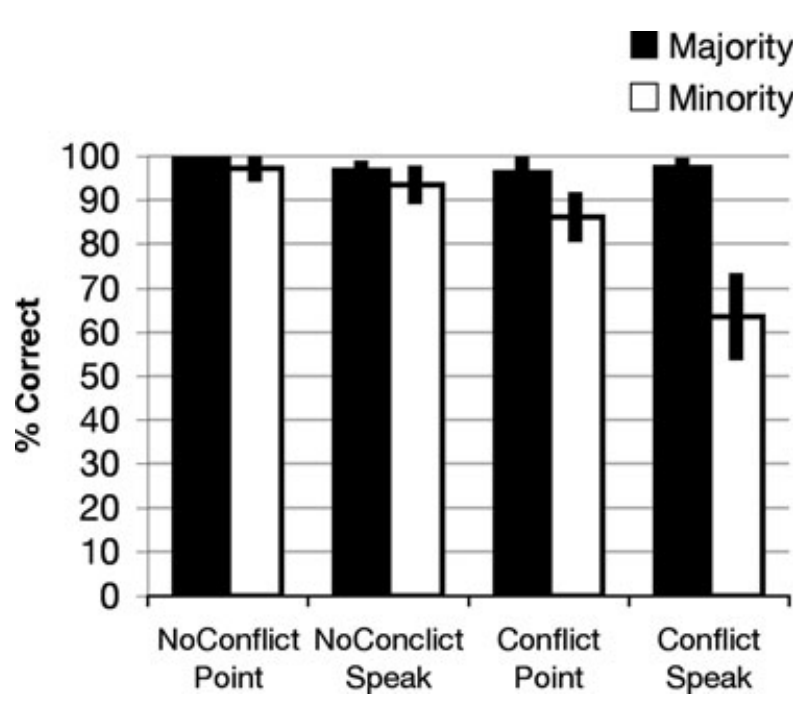

Figure 3. Mean percent correct $( \pm S E)$ for all four conditions of Experiment 2 for majority and minority children. 
performed significantly better when giving private compared to public responses (Figure 3). Similar to Study 1, children were significantly slower to respond in speak-conflict than in speak-no conflict trials (conflict: $M=1270 \mathrm{~ms}, S E=131$; no conflict: $M=777$ $\mathrm{ms}, S E=209) . t(17)=2.43$, Cohen's $d=1.2$.

Only looking at children's responses in the speak-conflict condition, minority children on average gave a correct account of the picture in front of them $64.8 \%$ of the time ( $S E=8.53$ ). On $31.5 \%$ of trials $(S E=8.15)$ they responded conform to the majority opinion, and on $3.7 \%$ of trials $(S E=1.56)$ they reported neither what was printed on the page nor the majority opinion. Of 18 children, 12 conformed at least once, out of whom 5 conformed more often than not. During debriefing, children were asked if they had noticed their book was different. Of the 18 sessions, 13 included clear video footage of who responded to the question. Of those 13 minority children only 4 stated to have realized their book to be different during debriefing. Of those 4 children, 3 conformed at least once, out of which one conformed more often than not. Like in Experiment 1, the level of conformity significantly decreased across speaking trials (Pearson's $r=-.61$, $N=28)$.

Responding by pointing minority children on average gave a correct account of the picture in front of them $86.1 \%$ of the time (SE $=4.1)$. On $9.3 \%$ of trials $(S E=2.77)$ they responded conform to the majority opinion, and on $4.6 \%$ of trials $(S E=1.81)$ they reported neither what was printed on the page nor the majority opinion. Of 18 children, only 8 conformed at least once, none of which conformed more often than not. The level of conformity stayed constant across pointing trials (Pearson's $r=-.17$, $d f=106$ ). In comparison, pointing and speaking resulted in equal amounts of incorrect responses, $t(17)=0.46$, but significantly different amounts of correct responses, $t(17)=2.9$, Cohen's $d=1.4$, and conform responses, $t(17)=-3.1, p<.05$, Cohen's $d=1.5$. Children conformed more when publicly responding than when privately responding.

\section{Discussion}

In Experiment 1 we showed that facing a unanimous majority, preschoolers often conformed despite knowing better. It remained unclear, however, if the motivation behind this behavior was to perform better, or social benefits.

Experiment 2 replicated Experiment 1 showing that children conform in conflict trials, despite performing at an almost perfect level individually.
Crucially, Experiment 2 showed that, given identical levels of conflict and exposure to peer opinion, children conform much more if their response is public (speak) than when it is private (point). They adapt their level of conformity to the privacy of their response flexibly from trial to trial. Surprisingly, Experiment 2 could not replicate the difference seen between boys and girls in Experiment 1. We have no satisfactory explanation for this.

\section{General Discussion}

The current studies demonstrate that children as young as 4 years of age are subject to peer pressure, indicating sensitivity to peers as a primary social reference group already during the preschool years. They often conform to a unanimous majority of three peers in spite better knowledge (strong conformity) out of social motivations mainly. Preschoolers' levels of conformity closely match those reported for adults (Asch, 1956). While they respond truthfully on the majority of trials, they conform to their peers in just over one third of trials in both experiments. Most strikingly, they adjust their level of conformity from trial to trial depending on the privacy of their response. This behavior is subject to different interpretations. On the liberal end, one could argue that children conform to manage the others' evaluations of their public self. This kind of behavior, however, has been argued not to be strategically used (AloiseYoung, 1993) or even understood (Banerjee, 2002) by children before around 8 years of age. To be slightly more cautious, one might argue that children realize the potential conflict that might arise from standing alone against a majority based on past experience. They might also remember from past experience that the best way to avoid such conflicts is by saying what everybody is saying. In the future, even more diagnostic experiments will have to dissect the exact mechanisms behind early conformist behavior. In addition, in adults different characteristics of the situation, such as size of the majority, the relation of the participant to the members of the majority and difficulty of the task have been shown to affect conformist tendencies. Similar consequences in children would support our hypothesis that the early strong social conformity we report here is adult-like in structure. How early it emerges in ontogeny remains another important question for future experimentation. The distinction between conformist behavior and the underlying motivation, as for the first time operationalized 
with young children in the present study, will be of utmost importance when investigating even younger ages. It might well be that children show conformist behavior following different motivations at different ages during development.

Conformity serves a crucially important function in the transmission of human culture by promoting quick and stable in-group uniformity, stabilizing between-group diversity (Boyd \& Richerson, 2009; Henrich \& Boyd, 1998; Henrich \& Henrich, 2007; Richerson \& Boyd, 2005). No other animal exhibits anywhere close to the kind of variability across populations as the human species. Even the other great apes, arguably some of the most cognitively flexible nonhuman animals, display only a relatively small number of stable behavioral differences across groups (van Schaik et al., 2003; Whiten et al., 1999). This fact becomes even more striking when one considers that humans vary much less genetically from each other than any other great ape species (Kaessmann, Wiebe, Weiss, \& Pääbo, 2001). While variation in ecology (Nettle, 2009) and even to some extent genetic variation (Dediu \& Ladd, 2007) account for some behavioral diversity across human groups, we propose that the difference in cross-group diversity between humans and other species is largely caused by a set of derived characteristics, perfectly setting up human children to adapt flexibly to social/cultural settings. These might, for example, include (a) a prolonged cranial ontogeny ensuring maximal cortical plasticity while individuals are already exposed to their social environment (Hublin, 2005), (b) an early advance of social-cognitive skills allowing superior access to social information through engagement (Herrmann, Call, Hernández-Lloreda, Hare, \& Tomasello, 2007; Tomasello, Carpenter, Call, Behne, \& Moll, 2005), and (c) be-like-you social learning in which the motivation to affiliate produces highly meansoriented imitative behavior (Call, Carpenter, \& Tomasello, 2005; Horner \& Whiten, 2005; Nielsen, 2009; Over \& Carpenter, in press). We suspect strong social conformity to be another addition to this list since as of yet there are no convincing demonstrations of strong conformity in other great ape species (for an alternative view, see Bonnie, Horner, Whiten, \& De Waal, 2007; Hopper, Schapiro, Lambeth, \& Brosnan, 2011; Whiten, Horner, \& de Waal, 2005).

In summary, the behavior documented here shows that children as young as 4 years of age are not only subject to adults' influence-which could easily arise from respect and fear of punishment-but also subject to social pressure from young peers. Sensitivity to peer pressure is a sign that even at this early age children are beginning to show the kind of conformist tendencies that are part of the foundation of human cultural diversity.

\section{References}

Aloise-Young, P. A. (1993). The development of self-presentation-self promotion in 6-year-old to 10-year-old children. Social Cognition, 11, 201-222.

Asch, S. E. (1956). Studies of independence and conformity: A minority of one against a unanimous majority. Psychological Monographs, 70, 1-70.

Banerjee, R. (2002). Children's understanding of self-presentational behavior: Links with mental-state reasoning and the attribution of embarrassment. Merrill Palmer Quarterly, 48, 378-404.

Barth, F. (1969). Introduction. In F. Barth (Ed.), Ethnic groups and boundaries (pp. 9-38). Boston: Little Brown.

Berndt, T. J. (1979). Developmental changes in conformity to peers and parents. Developmental Psychology, 15, 608-616.

Bishop, B. R., \& Beckman, L. (1971). Developmental conformity. Developmental Psychology, 5, 536.

Bond, R., \& Smith, P. (1996). Culture and conformity: A meta-analysis of studies using Asch's (1952b, 1956) line judgment task. Psychological Bulletin, 119, 111-137.

Bonnie, K. E., Horner, V., Whiten, A., \& De Waal, F. B. M. (2007). Spread of arbitrary conventions among chimpanzees: A controlled experiment. Proceedings of the Royal Society B: Biological Sciences, 274, 367-372.

Boyd, R., \& Richerson, P. (2009). Culture and the evolution of human cooperation. Proceedings of the Royal Society B: Biological Sciences, 364, 3281-3288.

Call, J., Carpenter, M., \& Tomasello, M. (2005). Copying results and copying actions in the process of social learning: Chimpanzees (Pan troglodytes) and human children (Homo sapiens). Animal Cognition, 8, 151-163.

Cialdini, R., \& Goldstein, N. (2004). Social influence: Compliance and conformity. Annual Review in Psychology, 55, 591-621.

Corriveau, K., Fusaro, M., \& Harris, P. L. (2009). Going with the flow: Preschoolers prefer nondissenters as informants. Psychological Science, 20, 372-377.

Corriveau, K., \& Harris, P. L. (2010). Preschoolers (sometimes) defer to the majority in making simple perceptual judgments. Developmental Psychology, 46, 437-445.

Costanzo, P. R., \& Shaw, M. E. (1966). Conformity as a function of age level. Child Development, 37, 967-975.

Dediu, D., \& Ladd, D. R. (2007). Linguistic tone is related to the population frequency of the adaptive haplogroups of two brain size genes, ASPM and Microcephalin. Proceedings of the National Academy of Sciences, 104, 10944-10949.

Dehaene, S., Izard, V., Spelke, E., \& Pica, P. (2008). Log or linear? Distinct intuitions of the number scale in Western and Amazonian indigene cultures. Science, 320, 1217-1220. 
Deutsch, M., \& Gerard, H. (1955). A study of normative and informational social influences upon individual judgment. Journal of Abnormal and Social Psychology, 51, 629-636.

Faul, F., Erdfelder, E., Lang, A.-G., \& Buchner, A. (2007). G*Power 3: A flexible statistical power analysis program for the social, behavioral, and biomedical sciences. Behavior Research Methods, 39, 175-191.

Gergely, G., Bekkering, H., \& Kiraly, I. (2002). Rational imitation in preverbal infants. Nature, 415, 755-755.

Goldstein, J., Davidoff, J., \& Roberson, D. (2009). Knowing color terms enhances recognition: Further evidence from English and Himba. Journal of Experimental Child Psychology, 102, 21-238.

Haun, D. B. M., \& Rapold, C. (2009). Variation in memory for body movements across cultures. Current Biology, 19, R1068-R1069.

Haun, D. B. M., Rapold, C. J., Call, J., Janzen, G., \& Levinson, S. C. (2006). Cognitive cladistics and cultural override in Hominid spatial cognition. Proceedings of the National Academy of Sciences, 103, 17568-17573.

Henrich, J., \& Boyd, R. (1998). The evolution of conformist transmission and the emergence of between-group differences. Evolution and Human Behavior, 19, 215-241.

Henrich, N., \& Henrich, J. (2007). Why humans cooperate: A cultural and evolutionary explanation. Oxford, UK: Oxford University Press.

Herrmann, E., Call, J., Hernández-Lloreda, M. V., Hare, B., \& Tomasello, M. (2007). Humans have evolved specialized skills of social cognition: The cultural intelligence hypothesis. Science, 317, 1360-1366.

Hopper, L. M., Schapiro, S. J., Lambeth, S. P., \& Brosnan, S. F. (2011). Chimpanzees' socially maintained food preferences indicate both conservatism and conformity. Animal Behaviour, 81, 1195-1202.

Horner, V., \& Whiten, A. (2005). Causal knowledge and imitation/emulation switching in chimpanzees (Pan troglodytes) and children (Homo sapiens). Animal Cognition, 8, 164-181.

Hublin, J. J. (2005). Evolution of the human brain and comparative paleoanthropology. In S. Dehaene, J.-R. Duhamel, M. D. Hauser, \& G. Rizzolatti (Eds.), From monkey brain to human brain: A fyssen foundation symposium (pp. 57-71). Cambridge, MA: MIT Press.

Kaessmann, H., Wiebe, V., Weiss, G., \& Pääbo, S. (2001). Great ape DNA sequences reveal a reduced diversity and an expansion in humans. Nature Genetics, 27, 155-156.

Ma, L., \& Ganea, P. (2009). Dealing with conflicting information: Young children's reliance on what they see versus what they are told. Developmental Science, 13, 151-160.

Majid, A., Bowerman, M., Kita, S., Haun, D. B. M., \& Levinson, S. C. (2004). Can language restructure cognition? The case for space. Trends in Cognitive Sciences, 8 , 108-114.

Malinowski, B. (1929). The sexual life of savages in northwestern Melanesia. London: Routledge.

Nettle, D. (2009). Ecological influences on human behavioural diversity: A review of recent findings. Trends in Ecology E Evolution, 24, 618-624.

Nielsen, M. (2009). The imitative behaviour of children and chimpanzees: A window on the transmission of cultural traditions. Revue de primatologie [online], 1, Document 5. Retrieved from http://primatologie. revues.org/254

Over, H., \& Carpenter, M. (in press). Putting the social into social learning: Explaining both selectivity and fidelity in children's copying behavior. Journal of Comparative Psychology. doi:10.1037/a0024555

Richerson, P., \& Boyd, R. (2005). Not by genes alone: How culture transformed human evolution. Chicago: University of Chicago Press.

Schwier, C., van Maanen, C., Carpenter, M., \& Tomasello, M. (2006). Rational imitation in 12-month-old infants. Infancy, 10, 303-311.

Segall, M., Campbell, D., \& Herskovits, M. (1963). Cultural differences in the perception of geometric illusions. Science, 139, 769-771.

Tomasello, M. (1999). The cultural origins of human cognition. Boston: Harvard University Press.

Tomasello, M., Carpenter, M., Call, J., Behne, T., \& Moll, H. (2005). Understanding and sharing intentions: The origins of cultural cognition. Behavioral and Brain Sciences, 28, 675-735.

van Schaik, C. P., Ancrenaz, M., Borgen, G., Galdikas, B., Knott, C. D., Singleton, I., et al. (2003). Orangutan cultures and the evolution of material culture. Science, 299, 102-105.

Walker, M., \& Andrade, M. (1996). Conformity in the Asch task as a function of age. Journal of Social Psychology, 136, 367-372.

Whiten, A., Goodall, J., McGrew, W. C., Nishida, T., Reynolds, V., Sugiyama, Y., et al. (1999). Cultures in chimpanzees. Nature, 399, 682-685.

Whiten, A., Horner, V., \& de Waal, F. B. M. (2005). Conformity to cultural norms of tool use in chimpanzees. Nature, 437, 737-740. 